\title{
Progress, challenges and opportunities for HIV prevention and control among high risk groups: a public health perspective
}

\author{
Renu Gupta ${ }^{1}$, Sarbjeet Khurana ${ }^{2}$, Ravinder Singh ${ }^{3}$ \\ ${ }^{1}$ Assistant Professor, Department of Microbiology,IHBAS \\ ${ }^{2}$ Associate Professor \&HOD, Department of Epidemiology, IHBAS \\ ${ }^{3}$ Associate Professor \&HOD, Department of Medical Anthropology, IHBAS \\ *Corresponding author E-mail: sarbjeetkh@gmail.com
}

\begin{abstract}
Aim of the study: To study various factors linked to the prevention and control of HIV-AIDS in the high risk groups in India. Objective of the study:

1) To study the socio-cultural and political obstacles in the prevention and control of HIV-AIDS in India.

2) To study the factors responsible for poor access of antiretroviral therapy (ART) in India.

Methodology: The relevant published literature was searched for studying various factors in the prevention and control of HIV-AIDS as well as for the factors responsible for the poor access of ART in India.

Observations: There are various socio-cultural issues/obstacles in prevention of HIV-AIDS in high risk group for e.g., gender inequality, power inequalities and male dominance; condom use believed to be in conflict with the cultural importance for procreation; poverty, illiteracy, increase in migrant population and unemployment; poor knowledge and awareness of reproductive and sexual health and sexuality; emergence of new urban sub-culture and physical or mental abuse at a young age. Lack of awareness and access to health care; misconceptions; stigma and discrimination, leading to secrecy of their high risk behavior and hence the further spread of the disease.

There are various political obstacles viz; HIV-AIDS control program has a focus on short term goals rather than long term sustainable achievements; minimal involvement of people living with HIV and AIDS in policy formulation and no political initiatives taken for family centered approach; lack of rights approach and control program lacks planning with regard to the structural factors existing in the country. There are various factors responsible for poor access of the population groups for ART viz; social factors like lack of awareness about HIV and availability of ART; long waiting hours at the ART centers etc.

Economic factors responsible for poor access of the population groups for ART are the costs of travelling to the clinic; shortage of doctors/paramedics for prescribing medicines, shortage of personnel/ trained counselors, shortage of testing facilities and inadequate laboratory support. Political factors leading to poor access of ART are lack of political initiative for expansion of services, submitting documents such as ration card/voter ID has been made mandatory for treatment, lack of consistency and coordination across services and the control program not reaching to the marginalized groups.
\end{abstract}

Keywords: HIV, AIDS, High Risk Groups, Socio-Cultural Factors, Political Factors, ART, Task Shifting.

\section{Introduction}

India has made tremendous progress in controlling HIV AIDS epidemic but it is still one of the most significant challenges of the new millennium. As a result of concentrated efforts and scaled up prevention strategies, interventions and access to treatment under NACP annual HIV incidence has declined by about $56 \%$ from 0.27 million in 2000 to 0.12 million in year 2011 with overall reduction in adult HIV prevalence from $0.41 \%$ in 2001 to $0.27 \%$ in 2011. Number of deaths due to AIDS related causes has also reduced by $29 \%$ from 2007. Despite substantial improvement, India is estimated to have third largest no. of people living with HIV AIDS in world after South Africa and Nigeria mainly due to its large population size rather than high prevalence (NACO Annual report 2012-13).

HIV epidemic in India is heterogeneous and concentrated in some states and in some high risk groups (HRGs). (Table 1)
The high prevalent states are Andhra Pradesh, Karnataka, Maharashtra, Manipur and Nagaland. Transgender, IV Drug users, Male having sex with male (MSM) and female sex workers (FSW) are main high risk groups which directly transmit the infection to the general population. Long distance truckers and single male migrants constitute a group which transmit the infection from high risk groups to the general population (Park 2013).

Table 1: Prevalence in the High Risk Groups in India

\begin{tabular}{lc}
\multicolumn{2}{c}{ Table 1: Prevalence in the High Risk Groups in India } \\
\hline High risk groups & Prevalence \\
\hline Transgenders & $8.82 \%$ \\
IV Drug user (IVDU) & $7.14 \%$ \\
Male who have sex with Male(MSM) & $4.43 \%$ \\
Female Sex Worker (FSW) & $2.67 \%$ \\
Truck drivers & $2.59 \%$ \\
Migrants & $0.99 \%$ \\
\hline
\end{tabular}

Migrants

Control of HIV epidemic requires concentrated focussed efforts towards numerous socio-cultural and political issues which chal- 
lenge HIV prevention and control among these vulnerable/high risk groups.

\section{Challenges in HIV Prevention and control in the high risk groups}

There are several obstacles which need to be considered while developing policy interventions aimed at reducing burden of HIV in the high risk groups.

\subsection{Socio-cultural factors posing as obstacles}

Generally women and girls are discriminated in our country. They are unaware of their rights and have little or no power in the family matters. Indian society is highly patriarchal and hence most permissive for men. This social power structure tolerates forms of risky behavior like having multiple sex partners, marrying girls early, alcoholism, drug addiction makes home women vulnerable to HIV infection. Physical and sexual violence, rape, marital rape, sex without consent have emerged as common as everyday mundane. Women do not have more power and choices to condoms use, sex refusal under any medical / physical condition. Sex workers are commonly facing them. Sufferings of stigma as well as discrimination are pushing them to marginalization turning them to fear of disclosure and seeking less health services. Their social vulnerability is further enhanced by the gender inequalities, social values that restrict education regarding sexuality.

There is a need for creating an environment in which they can have an open and honest dialogue with the clients (Israel etal 2008, Platt etal. 2013). The most important issue is that if we want to improve the conditions of sex workers and want to empower them to overcome the power inequalities with their clients then we need to focus our attention towards decriminalization of sex work. Decriminalization of sex work is a prerequisite to changing cultural norms regarding the sex workers.

Some of these factors are relevant at the family level, others at the community level and its local bodies and some others are concerned at the State level. All these factors should be considered in developing a policy for the stigma and discrimination-free social environment for women, girls and the sex workers. There are several behavioural issues at family level - disturbed emotional development, childhood abuses, violence, prejudice, arrest and harassment, use of alcohol and recreational drugs, injecting drugs or selling sex for drugs, women rights of inheritance in property etc. must be controlled. Physically and financially powerful men force boys into homosexuality and push girl children in flesh trade. Those who have been abused or battered at a young age are psychologically fragile and adopt such risky behaviours in adult. Similarly, the violence at their settings exacerbates their vulnerability and risk. Refusing sex or advising the use of condom by the wife leads to aggressive, forced and violent behaviour of husband which further makes women vulnerable to genital injuries and hence HIV. Prejudice, arrest and harassment stigmatize sex workers and jeopardize the successful implementation of prevention program. The police and the judiciary system still carry their judgemental biases towards these groups. Strategy for sensitisation of these groups should be envisaged in the policy of the program. Alcohol and drugs behaviour or selling sex for drugs in the settings or environments where the sex workers are, is common as they are perceived to be aphrodisiacs. These increases the probability of HIV transmission among them, evidence suggests that sex work is associated with HIV sero-conversion among women who inject drugs (Kral etal. 2001, Wood etal. 2007). A component on awareness targeting alcohol and drug use should form the component of the policy for this high risk group. Widows have to marry husband's brother or any other relative from husband's family as a form of social protection. The risk posed by this practice are those if the widow is HIV positive the inheritor is at risk and equally the widow is at risk if the inheritor is HIV positive.
The community and its local bodies can also help in preventing and controlling the unsafe sex. These community organizations may check violence, prejudice, arrest and harassment of these workers and criminal activities towards the sex workers in their areas of high risk of HIV transmission. They are stigmatized and marginalized which jeopardize successful implementation of prevention program. The police and the judiciary system still carry their judgmental biases towards these groups. Increase in migrant population in search of jobs compounded with long working hours, isolation from family leads to increased sexual risk and increases vulnerability to acquire infection and enhanced risk of transmission to their spouses. Poverty, unemployment and poor socioeconomic conditions force women use sex for economic reason. There is misconception e.g. HIV is transmitted via vaginal sex or sex workers but not by alternate oral and anal sexual practices. It leads to increase number of Transgender and men- sexmen (MSM). The community and its local bodies can be very helpful in checking, preventing or solving these issues. Similarly, State and voluntary organizations may play a role in reducing power inequalities and restricted use of alcohol and drugs through enacting the laws (NACO Annual report 2012-13, Park 2013).

\subsection{Political obstacles}

Political obstacles are the political challenges which need to be overcome to improve HIV prevention measures in India. National AIDS Control Program has come a long way in addressing various barriers. Yet, there are various political obstacles which need to be addressed:

- Each state in India is bigger than many small countries, and each has a different epidemic with distinct vulnerability. Effective response calls for decentralised decision making, diverse resource persons and capacity building at both state and national level.

- HIV prevention has received huge external funds from international agencies which have been utilised for achieving the short term goals rather than long term sustainable achievements.

- There is a minimal involvement of people living with HIV and AIDS in policy formulation. Various studies in India have reported that immediate concerns of HRGs are harassment, discrimination and violence coming from police, their partners and the general public for whom there has been no advocacy movements.

- There has been no political initiative for family centred approach, wherein the concept is to cater to not only the HIV case but also his family members. Politically and legislatively there is a lack of the rights approach which should recognise the population's rights including the sexuality and to have children etc.

- Politicians also have their own biases pertaining to HIV and various events have revealed the conservative and discriminatory approach of the politicians especially towards the high risk groups like sex workers, MSM etc.

- The NACP program mainly targets the individual behavioural modifications but lacks planning with regard to the structural factors which are actually responsible for the behaviour of individual's viz. poverty, gender, age, policy and power (Densham 2006, Jurgens 2007, Fox etal 2011, Hunsmann 2012).

There are various political allies that support HIV preventive measures. Alliance India supports the actual delivery of services through community based HIV programs (Alliance India). It mainly supports the program through capacity building, technical support, knowledge sharing and advocacy. There are many nongovernmental organisations (NGOs) and community based organisations (CBOs) in India working in the field of HIV and AIDS--.CHETNA Koshish, Pehchaan and Avahan, Community action on harm reduction for people who use drugs, Community Health Action Network (CHAN), The NAZ Foundation (India) Trust, AIDS Awareness Group (AAG), Gujarat AIDS Awareness 
and Prevention Unit and the South Indian AIDS Action Program (SIAAP)

These NGO and CBO work in the targeted interventions with the key populations, direct care of the people living with HIV, general awareness campaigns and care for the children orphaned by AIDS. Some of these organisations have also piloted certain approaches to tackle the stigma and discrimination.

\section{Factors responsible for poor access of ART in India}

India had an estimated 2.4 million PLHIV in 2009, less than half of those requiring ART were receiving treatment (UNAIDS, 2014). HIV testing and ART is available in all the districts of the country, free of cost. There are various factors responsible for poor access of the population groups for ART (Pop council 2012, Patel etal. 2014)

\subsection{Social factors}

- Lack of awareness about HIV and availability of ART.

- HIV positive women are thrown out of their home or widows are forced to run their households with no family support. Accessing ART becomes secondary for them.

- Stigma and discrimination force high risk groups to hide their status. Their utilisation of treatment is also affected by the discriminatory experience of the peers at the health facility.

- Long waiting hours at the ART centres which hamper their routine work as well as leads to loss of wages for the day.

- Due to faith in the traditional healers many HIV positive cases either do not start ART or they stop ART after initiation on the advice of the traditional healers

- Inadequate community sensitization and limited involvement of the community in the program planning process

\subsection{Economic factors}

- Most common factor affecting the access of ART is the costs of travelling to the clinic. The people living with HIV have to travel long distance to reach the ART centres. They have to take a day off which leads to loss of wages.

- Drugs for treatment are very costly, unaffordable and not easily available at all the level of health care facility.

- Shortage of doctors/paramedics for prescribing medicines

- Shortage of personnel/ trained counselors to explain treatment options during primary counseling for HIV testing

- Time loss of patients in seeking medical care leading to in come loss (travel, waiting time)

- Shortage of testing facilities for $\mathrm{Cd} 4$ count and HIV viral loads

- Inadequate laboratory support and differential methods of screening in different centre's

\subsection{Political factors}

- Certain states (Tamil Nadu) are functioning much better than others (U.P.) as the public health infrastructure is not well developed in all the states. There appears to be lack of initiative for expansion of services.

- Requirement of submitting documents such as ration card/voter ID is mandatory for registration at the ART centers. These are difficult to procure for the temporary residents who are hence not able to access the ART facilities.

- Lack of consistency and coordination across services/ existence of other competing interests.

- Program not reaching to ground level (rural population, marginalized groups) where there is actual need.

- Differential support for testing and access to treatment.
- Testing and treatment services not available in the same centre.

- Corruption leading to partial/shortage of drug supply.

\section{To overcome the problem of inadequate ac- cess to HIV treatment some recommenda- tions are}

- Information education and communication (IEC) regarding availability of free treatment. Informing the clients at the posttest counselling that no delays should be there for initiation of ART. They should also be informed about the documents needed for registration at the ART centre.

- Training of staff with the aim of having supportive behaviour for ensuring the treatment access.

- Empowerment of women and marginalized population by providing social and economic support, addressing social injustice and inequality

- Creating supportive non-discriminatory environment towards PLHIV

- Awareness and knowledge dissemination that AIDS is curable and ways to access treatment

- Decentralization of HIV AIDS control program to field level with adequate financial and administrative delegation of responsibilities.

- Capacity building, Service improvement in delivering diagnostic and treatment under one roof

- Uninterrupted drug supply and motivation to maintain adherence

- Incentives for affordable drug research

- Community sensitisation and involvement of those who need in planning process

- Monitoring and analysing treatment effectiveness in morbidity and mortality of PLHIV.

- Legal perspectives if treatment is denied

\section{Considering the concept of task shifting as a solution}

According to WHO:

- The world is experiencing a chronic shortage of well-trained health workers.

- A total of 57countries, mostly in sub-Saharan Africa but also including Bangladesh, India and Indonesia, face crippling health workforce shortages.

- WHO estimates that more than 4 million health workers are needed to fill the gap

- The global deficit of doctors, nurses and midwives is at least 2.4 million (Patel etal. 2012).

WHO, in collaboration with the Office of the United States Global AIDS Coordinator (OGAC) launched the WHO/OGAC Task Shifting Project for training the non - physicians especially nurses to take over the responsibility of initiation and maintenance of ART. Assefa etal. 2012, Bedelu etal 2007 and Sherr etal 2010 conducted retrospective cohorts to examine the outcome of task shifting (Bedelu etal. 2007, Sherr etal. 2010, Assefa etal. 2012). A systematic review of task shifting in care of patients with HIV infection showed that it is an effective strategy for addressing shortages of Human Resource Health in HIV treatment and care (Callaghan etal. 2010).

There are 3 randomised control trials by Jafar etal. 2009, Selke etal. 2010, Sanne etal. 2010 who have also reported that task shifting showed no differences in virological or mortality outcomes between groups, non-inferior treatment failure and retention outcomes. 
Fairall etal conducted a Randomised clinical trial which further enhanced our knowledge regarding the value of task shifting (Fairall etal. 2012). It has reliably provided evidence that there is

- No difference in mortality between the patients initiated and followed up by nurses compared to those seen by the doctors.

- The nurse initiated and maintained ART improves retention and minimizes the number of patients lost to care compared to those seen by doctors.

- Outcome in terms of the difference in the means of CD4 counts followed up by nurses and doctors as 22.3 cells $/ \mathrm{mm} 3$ (95\% CI 3.6-40.9), $\mathrm{p}=0.02$, favouring the nurses care.

- No difference between two cohorts for viral suppression.

- For initiation of ART, cohort 1 reports the adjusted hazard ratio for time to initiation as $1.14, \mathrm{p}=0.23$.

- In cohort1 there was better detection/diagnosing of TB by nurses compared to doctors, whereas in Cohort 2 the rates were same for doctors or nurse.

\subsection{The public health and policy implications of task shifting in HIV program in India}

Task shifting is preferred to overcome the shortage of manpower in many countries but the legislation in many countries including India permits only doctors to prescribe ART, hence there is a need for policy change and legal protection for the nurses to take up the new roles. Secondly the task shifting may reduce costs in certain circumstances but the successful implementation would require additional resources. Thirdly it is important to identify the tasks which can be safely shifted without compromising on the quality of care.

Various studies have provided evidence that task shifting will be beneficial to the patients as they will be able to avail the services in close proximity with better service quality. The Patient satisfaction would improve because of decreased waiting time, decrease spending on transportation and no loss of wages.

Doctors would be able to use their expertise for complicated cases. There would be good clinical outcomes in terms of survival rates. The co-morbidities (T.B.) would be detected early as the frequency of contact with the health functionary and accessibility of care would be prompt. There would be positive impact on health workers and increased job satisfaction.

\section{The various issues to consider while imple- menting task shifting are (WHO 2007, USAIDS 2010)}

Task shifting from the doctors to nurses should happen hand in hand with the policy or legislative reforms as the nurses should be protected legally for their new or additional tasks. There is a need of the strategic plan to ensure adequate resources as well as commitment from all the stakeholders for sustainability of the plan. Continuing education and training programs would then be necessary for health workers to recognise their own responsibility The negative impacts if at all will be more on the manpower side viz;

- The staff burnout ,lack of motivation if there are no financial or nonfinancial incentives, low performance if de-motivated workers are inducted in the programs

- Finally there can be financial implications on the system (WHO 2007).

\subsection{Factors affecting task shifting implementation pro- cess are (Ihuoma etal. 2010)}

- Resistance to Organizational Change

- Training of Staff Implementing Task Shifting

- Roles and Competency Requirements

- Inadequate funds, equipment, supplies \& infrastructure
Resources required for Implementation of Task Shifting (Ihuoma etal. 2010, Smith 2010)

- Support in terms of supplies i.e. the ART drugs have to be ensured because if the drugs would not be provided then the objective of providing treatment to HIV AIDS patients would not be served.

- Supervision and coordination by the superiors (as in DOTS program for TB) within the existing health services is needed so that the quality of care does not suffer.

- Resources for training of workers as this is crucial, and the length and content of trainings depend on prior knowledge, tasks, and roles to be fulfilled by these workers in future. These training components would require resources in terms of manpower of trainers, budgetary allocation for trainings etc.

- Adequate remuneration or additional money would be required for the additional tasks performed by the workers as an incentive and to carry on the work with motivation.

- Budgetary allocation for monitoring and evaluation of the tasks performed would also be required for bringing about any further changes.

\section{Summary}

HIV-AIDS is one of the most significant challenges of the new millennium. The Control of HIV epidemic requires concentrated focused efforts towards numerous socio cultural, political, economic issues which challenge HIV prevention and control among the vulnerable/high risk groups. To overcome the poor access of ART in India, task shifting from the doctors to nurses can be tried which should happen hand in hand with the policy or legislative reforms.

\section{References}

[1] National AIDS Control Organisation, Annual report 2012-13. Available

http:nacoonline.org/upload/AR\%20200910/NACO_AR_English\%20c orrected.pdf (accessed February 18, 2014).

[2] Park K (2013). Park's Textbook of Preventive and Social medicine. Banarsidas Bahnot, Delhi, India. 22nd ed, Pg316-327

[3] Israel E, Laudari C, Simonetti C (2008) HIV Prevention among Vulnerable Populations. Pathfinder International Technical Guidance Series Number 6.

[4] Platt L, Jolley E, Rhodes T, Hope V, Latypov A, Reynolds L, Wilson D (2013) Factors mediating HIV risk among female sex workers in Europe: a systematic review and ecological analysis. BMJ Open; 3:e002836.doi:10.1136/bmjopen-2013-00283.

[5] Kral AH, Bluthenthal RN, Lorvick J, Gee L, Bacchetti P, Edlen BR (2001) Sexual transmission of HIV-1 among injection drug users in San Francisco, USA: risk-factor analysis. Lancet 357, 1397-401. http://dx.doi.org/10.1016/S0140-6736 (00)04562-1.

[6] Wood E, Schachar J, Li K, Stolltz JoA, Shannon K, Miller C, Smith EL, Tyndall MW, Kerr T (2007) Sex trade involvement is associated with elevated HIV incidence among injection drug users in Vancouver Addict Res Theory 15, 321-5. http://dx.doi.org/10.1080/16066350701254258.

[7] Densham A (2006). Politics as a Cause and Consequence of the AIDS Pandemic. Perspectives on Politics 4, 641-46. http://dx.doi.org/10.1017/S1537592706220383.

[8] Jurgens R (2007) Taking action against HIV. A handbook for parliamentarian's no.15. Available at www.ipu.org/pdf/publications/aids07e.pdf (accessed on January 12, 2014).www.allianceindia.org (accessed 21st February 2014).

[9] Fox AM, Goldberg AB, Gore RJ, Bamighausen T (2011). Conceptual and methodological challenges to measuring political commitment to respond to HIV. J Int AIDS Soc 14, S5. http://dx.doi.org/10.1186/1758-2652-14-S2-S5.

[10]Hunsmann M (2012) Limits to evidence-based health policymaking: Policy hurdles to structural HIV prevention in Tanzania Social Science \& Medicine doi:10.1016/j.socscimed.2012.01.023. http://dx.doi.org/10.1016/j.socscimed.2012.01.023.

[11]UNAIDS World AIDS day. Available at www.unaids.org/en/media/unaids/contentassets/documents/epidemiol ogy/2010accessed on January 30,2014 
[12]Factors affecting access to and enrolment in ART services 2012.Available www.popcouncil.org/pdfs/events/2012ias_battala.pdf

[13]Patel S, Baxi RK, Patel SN, Golin CE, Mehta M, Bakshi H, Shingrapure K, Modi E, Coonor P, Mehta K. Perceptions regarding barriers and facilitators to combination antiretroviral therapy adherence among people living with HIV/AIDS in Gujarat, India: A qualitative study. Indian J Sex Transm Dis 2012; 33:107-11 http://dx.doi.org/10.4103/0253-7184.102119.

[14]WHO. Treat Train Retrain. Task shifting: Global recommendations and guidelines. Geneva: World Health Organization; 2007. http://data.unaids.org/pub/Manual/2007/ttrtaskshiftingen.pdf (accessed on 21 st Feb 2014).

[15]Bedelu M, Ford N, Hilderbrand K, Reuter H (2007). Implementing antiretroviral therapy in rural communities: the Lusikisiki model of decentralized HIV/AIDS care. Journal of Infectious Diseases 196(Suppl 3), S464-8. http://dx.doi.org/10.1086/521114

[16]Sherr KH, Micek MA, Gimbel SO, Gloyd SS, Hughes JP, JohnStewart GC, Manjate RM, Pfeiffer J, Weiss NS (2010). Quality of HIV care provided by non-physician clinicians and physicians in Mozambique: a retrospective cohort study. AIDS 24(Suppl. 1), S5966. http://dx.doi.org/10.1097/01.aids.0000366083.75945.07.

[17] Assefa Y, Kiflie A, Tekle B, Mariam DH, Laga M, Van Damme W (2012). Effectiveness and acceptability of delivery of antiretroviral treatment in health centres by health officers and nurses in Ethiopia. Journal of Health Services Research \& Policy 17(1), 24-9. http://dx.doi.org/10.1258/jhsrp.2011.010135.

[18]Callaghan et al. Human Resources for Health 2010, 8:8 http://www.human-resources-health.com/content/8/1/8). http://dx.doi.org/10.1186/1478-4491-8-8.

[19]Jaff ar S, Amuron B, Foster S, Birungi J, Levin J, Namara G, Nabiryo C, Ndembi N, Kyomuhangi R, Opio A, Bunnell R, Tappero JW, Mermin J, Coutinho A, Heiner Grosskurth H (2009) Rates of virological failure in patients treated in a home-based versus a facility-based HIV-care model in Jinja, southeast Uganda: a cluster-randomised equivalence trial. Lancet 374, 2080-89. http://dx.doi.org/10.1016/S0140-6736 (09)61674-3.

[20]Selke HM, Kimaiyo S, Sidle JE, Vedanthan R, Tierney WM, Shen C, Denski CD, Katschke AR, Wools-Kaloustian K. (2010). Task-shifting of antiretroviral delivery from health care workers to persons living with HIV/AIDS: clinical outcomes of a community-based program in Kenya. J Acquir Immune Defic Syndr 55, 483-90. http://dx.doi.org/10.1097/QAI.0b013e3181eb5edb.

[21] Sanne I, Orrell C, Fox MP, Conradie F, Ive P, Zeinecker J, Cornell M, Heiberg C, Ingram C, Panchia R, Rassool M, Gonin R, Stevens W, Truter H, Dehlinger M,van der Horst C, McIntyre J, Wood R; CIPRASA (2010) Nurse versus doctor management of HIV-infected patients receiving antiretroviral therapy (CIPRA-SA): a randomised noninferiority trial. Lancet 376, 33-40. http://dx.doi.org/10.1016/S01406736 (10)60894-X.

[22]Fairall L, Bachmann M, Lombard C, Timmerman V, Uebel K, Zwarenstein M, Boulle A, Georgeu D, Colvin CJ Lewin S, Faris G, Cornick R, Draper B,Tshabalala M, Kotze E, van Vuuren C, Steyn D, Chapman R, Bateman E (2012) Task shifting of antiretroviral treatment from doctors to primary-care nurses in South Africa (STRETCH): a pragmatic, parallel, cluster-randomised trial Lancet 380, 889-98. http://dx.doi.org/10.1016/S0140-6736 (12)60730-2.

[23]USAIDS (2010).Creating an enabling environment for task shifting in HIV and AIDS services: Recommendations based on two African Country case studies. Retrieved from www.hciproject.org/communities/chw-central/resources/creatingenabling-environment-task-shifting-hiv-and-aids-services (accessed on 21February 2014).

[24]Ihuoma E, Caroline O, Irene E, Emily U, Asabe G (2010) Task Shifting -A Strategic Response to the Health Care Human Resource Crises: A Qualitative Study of Hospital Based HIV Clinics in North Central Nigeria, Office of Maryland, School of Nursing.

[25]Smith, Tamara (2010) Task-Shifting in Health Care Settings, Desk Review. Arlington, Va.: USAID | AIDSTAR-One Project, Task Order 1, 2010. Available at www.aidstar-one.com. (Accessed February 21 2014). 